\title{
Soybean Research and Development in Ethiopia
}

\section{Deresse Hunde Desissa*}

Associate Researcher, Soybean breeder(Breeding and Genetics), Ethiopian Institutes of Agricultural Research(EIAR), Pawe Agricultural Research center (PARC)

*Corresponding Author: Deresse Hunde Desissa, Associate Researcher, Soybean breeder(Breeding and Genetics), Ethiopian Institutes of Agricultural Research(EIAR), Pawe Agricultural Research center (PARC). E-mail: deressehunde20@gmail.com

Received: September 19, 2019; Published: September 27, 2019

DOI: 10.31080 /ASAG.2019.03.0668

\section{Soybean research system in Ethiopia}

Soybean research started in Ethiopia after its introduction to the country since1950 under Institute of Agricultural Research (IAR), since 1970 at Hawassa, Jimma, Bako and Pawe, during this time firstly five soybean varieties was legally registered in 1973/74. Following two strategies are being followed: 1) Introduction of finished soybean Technology/Released variety/and germplasm/unreleased variety/from external sources IITA (International Institutes of Tropical Agricultural Research), Nigeria, Malawi, Birazile, China, and USDA. 2) Crossing and hybridization of soybean variety to increase variability and generates good quality with productive soybean variety and this continued up to 2007 and registered 23 soybean variety for production in Ethiopia. This variety was adapted to low land, mid altitude and long growing season from North West to south western parts of the country. This variety was classified in to three maturity class and testing locations: (1) Early maturity class and testing location is at short growing season (moisture stressed areas) such as Humera, Hawassa, Reftvaly areas Mankush and south omo area. Under this class variety registered includes: Awassa-95, Williams, Crawford, Nova, Nyala, Cheri, Gozelle, and Awassa-04. (2) Medium maturity class and testing location includes: Bako, Jimma, Maitsebri, Dansha, and dibate and aother similar areas and variety registered for this area includes: Coker-240, Boshe, Jalele, wello, Davis, Afgat, Gizo, Gishama, Clark-63k in medium growing season of the country. (3) Late maturing class and testing locations are: Pawe, Asosa, Arbaminch, Dhidhessa and similar agro ecology of the country. Variety registered for this long growing season includes: Belessa-95, Wegayen, Ethio-yugozilava (TGX-1332644), keta, and korme, Dhidhessa, Pawe-1, Pawe-2 and Pawe-3. Further research activity currently under the way on all this testing locations mentioned above to develop stable, high yielding and resistant to stress (both biotic and a biotic) in the country.
Pawe Agricultural Research Center in particular with Jimma and other collaborative centers were working a research on soybean in all disciplines includes: Variety development research (Breeding and Genetics research), Agronomy research, Crop protection research (pest and disease control, Soil fertility regulation research, food and nutritional quality laboratory research and Socio economic research. Soybean varietal development through conventional breeding methods that involves germplasm introduction, selection, crossing and hybridization followed by advancing generation plays a great role on soybean technology generation. Crossing and hybridization of soybean in Ethiopia were started since 2011/12 particularly at jimma and Pawe to increase genetic diversity in line with acceptable, stable and new varietal development).

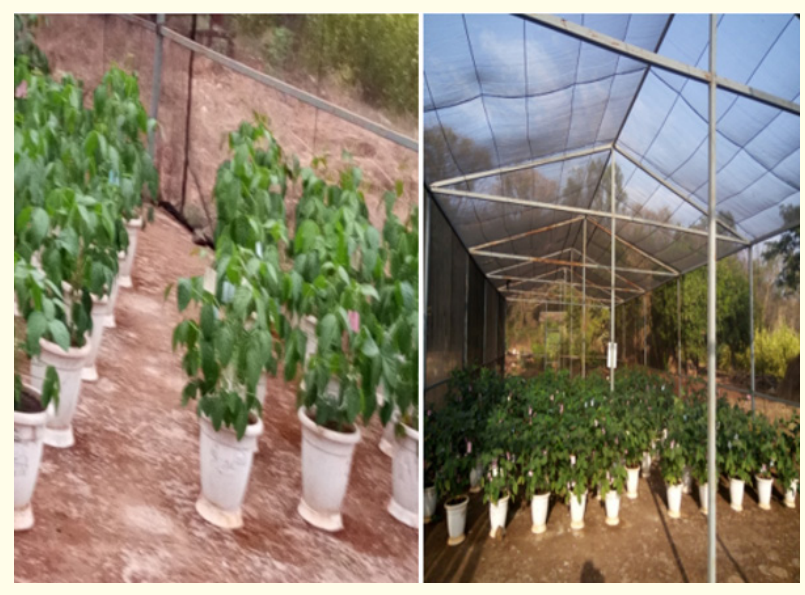

Figure 1: One means of increasing Genetic variability is through crossing and hybridization Research that performed at Pawe Research Center during off season in the lath house to generate soybean inbreed lines Crossing and hybridization at Pawe Research Center in 2019 offseason. 
Soybean research and technology generation in Ethiopia

Soybean research system in the country strategically started fron the year of its introduction and mainly focused on: Development of high yielding and stable, acceptable nutritional composition, resistant to biotic stress (disease, pest and nematodes) and a biotic stress (Acidity, salinity, drought and frost) variety and identify major soybean pests, basic knowledge, information and IPM options in line with appropriate agronomic practices, cropping systems and efficient bio-fertilizer technologies application for soybean in different soybean growing agro-ecologies, to overcome sustainable production, productivity, natural resource utilization and conservation and assess production constraints and opportunities, analyze value chain and production economics and the adoption and impact of improved soybean technologies for major producing agro-ecologies to demonstrate, popularize and promote, multiply and supply improved soybean finished technologies including food recipes and post-harvest handling of soybean seed. Hence, the soybean research in the country contributes altos of technology that plays a significant role for users

Soybean Technology generated through varietal development

In Ethiopia currently 26 different soybean released Varieties are available on production of this (8 early maturing variety/for short growing season or moisture stressed agro ecology of Ethiopia, 9 medium maturing variety for mid altitude agro ecology of the country and 9 let maturing variety for long growing agro ecology of Ethiopia) were released from national and regional research centers and available in Ethiopia. In order to solve the rain feed dependence cropping system in Ethiopia, Pawe research center also started soybean research under irrigation since 2017 to identify the yield potential and water response of soybean under irrigation and to select best performing variety under irrigated lands of Ethiopia that aimed to solve the most critical problem of climatic change impacts on agriculture specially for those countries depend on rain feed agriculture system (Figure 2).

Pawe Research Center recently released soybean variety (Pawe1, Pawe-2 and Pawe-3 for medium to long growing season of Ethiopian agro ecology and the variety Pawe- 3 with its important traits includes high oil content (23\%), protein content (42\%) and high canopy coverage/many leafs to regulates soil fertility/followed by Pawe-1 and Pawe-2 (Ministry of Agriculture, 2013). The yield potential of the recently released Soybean variety is up to $50 \%$ and the optimum yield/national average yield of the crop in country is 2.2 tons and the attainable yield of the crop through the best available technology and skill was 2.9 tons on research and actual yield of the crop is 2.3 tons at farmers managed field condition this reflect the current state of soils and climate, average skills of the farmers, and their average use of technology.

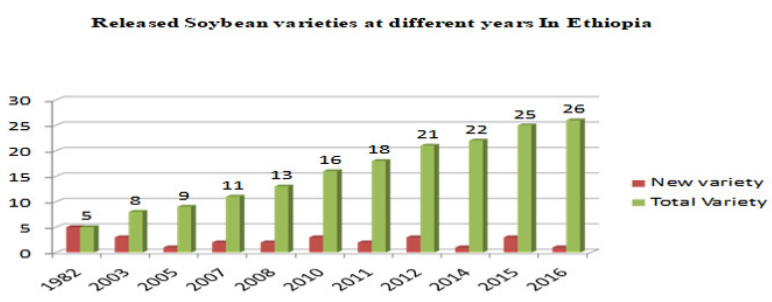

Figure 2: Graphical presentation of 26 Released Soybean Variety by National and Regional Research Centers by year in Ethiopia.

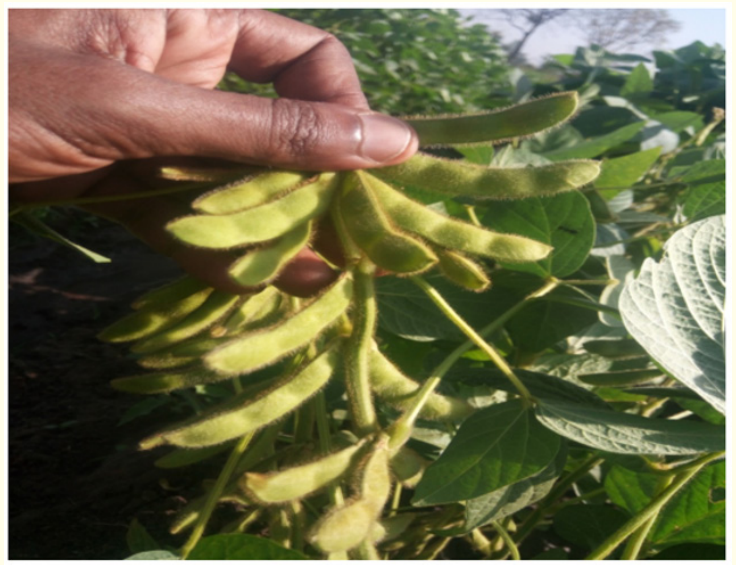

Figure 3: Recently released Soybean variety (Pawe-1) at Pawe Research Center that demonstrated and selected by farmers and all stake holders over three woredas in Metekel zone north western Ethiopia.

Therefore the yield gap is the difference between the two levels of yields which is 0.6 tones. The exploitable yield gap accounts for both the unlikely alignment of all factors required for achievement of potential or water limited yield, the economic management and environmental constraints that preclude, for example, the use of fertilizer rates that maximize yield, when growers' aim is often a compromise between maximizing profit and minimizing risk at the whole-farm scale, rather than maximizing yield of individual crops (Evans and Fischer 1999). Using this dynamic perspective, we can concluded that allowance for the temporal temperature change showed that the returns from improved crop management 
and breeding were superior to those suggested by the increase in actual yield (Hall., et al. 2013).

Future opportunities and prospects of soybean production in Ethiopia

The current Soybean production in small farmers or large scale is highly dependent on marketable value and suitability of the environmental conditions especially in the lowlands of North western and Southwestern part of the country. The suitability of potential environmental opportunity for Soybean crop production and the presence of the yield potential of Soybean in Ethiopia would give better image and possibility for yield gap improvement. The proximity of the country to international market and the high market demand for Ethiopian Soybean seed/especially organic soybean seed/can be considered as another opportunity. The oil qualities of varieties currently under production are relatively good and encouraging but needs to improve further that targeted to the customer traits of interest. Though there is an effort by some research centres in Ethiopia in variety development and agronomic research practices, but yet it is not enough to bring impact in increasing production and productivity in line with increasing soybean seed system. Therefore one of the most important means of increasing soybean production and productivity in line with increasing soybean seed system is expanding, addressing and pushing soybean crop towards the competitive crops belts like maize and sesame.

\section{Future soybean research direction in Ethiopia}

To solve different challenges that soybean production and productivity faces in Ethiopia the future direction of research should focus on improving soybean production, productivity as well as quality of Soybean crop through the use of improved technologies is highly recommended. Thus, it is important to focus on, Client Preferences that understanding the needs and preferences of small holder farmers, processors, traders, retailers, consumers and other actors along a value chain, development of high yielding potential variety with improved quality traits (edible oil) through application of modern breeding techniques. Development of improved agronomic and managmental practices to met the yield potential of the crop. One way of solving such problem is through integration that involving public and private sector expertise and integrates the best practices from the two sectors into the variety development process. The need of the collaborative efforts of all concerned stakeholders should include government organizations, researchers, NGOs, private investors and farmers in the improvement program of the crop. In addition to this the future research should targeted on introduction and identification of better adaptable cultivars with better resistance to various environmental changes that brought about by the climate change that limit crop yields specially heat and water stresses will be considered as the most important limiting factors and increasing prevalence of diseases and pests, therefore, during development of drought resistant variety of soybean for drought porn areas the country in line with Market research to define the performance, standard and priority of each varietal characteristics and to test for validation key assumptions should be throughout variety development process and Capacity building on Soybean crop improvement and post harvest handling to maintain the quality of soybean produced. Attention should be given to start refining processes for oil seeds in Ethiopia than importing refined edible oil with comparable value that is being obtained from expert earnings from oilseed and environmental clustering for high oil quality, as oil quality is influenced by environmental factors.

\section{Volume 3 Issue 10 October 2019 (C) All rights are reserved by Deresse Hunde Desissa.}

